\title{
A IMPORTÂNCIA DE ATIVIDADES PRÁTICAS PARA O DESENVOLVIMENTO PROFISSIONAL DO ENGENHEIRO
}

Cleydson Matos Lima - cleydsonmatos12@ hotmail.com

Alan Patrick Martins Reis - alanreis734@ gmail.com

Jamilly Cristina Azevedo da Silva - jamillyazevedo123@gmail.com

Suelem Karolina Souza Silva - suelemkarolina96@gmail.com

Yukie Fujihara - yukiefujihara@ hotmail.com

Carminda Célia Moura de Moura Carvalho - carminda@ufpa.br

Universidade Federal do Pará, Faculdade de Engenharia Elétrica e Biomédica

Rua Augusto Corrêa, 01 - Guamá

66075-110 - Belém - Pará

Resumo: A aplicação dos conhecimentos adquiridos no ambiente acadêmico proporciona uma aproximação entre a teoria e a prática. Assim, este artigo foi elaborado com base em um levantamento sobre a importância da aprendizagem prática para os discentes de Engenharia Elétrica da Universidade Federal do Pará participantes de atividades extensionistas promovidas pelo Laboratório de Tecnologias Avançadas em Iluminação e Instalações Elétricas do CEAMAZON (Centro de Excelência em Eficiência Energética da Amazônia) e para os já graduados que passaram pelo citado laboratório. A atuação na elaboração de projetos elétricos, em experiências de instalações elétricas e em monitorias em minicursos, permite um domínio maior dos conhecimentos absorvidos nas disciplinas teóricas e normas técnicas. As situações e dificuldades encontradas durante a execução dessas atividades ajudam os alunos a desenvolverem um caráter profissional, e consequentemente, promovem uma melhor preparação para as atividades encontradas no mercado de trabalho.

Palavras-chave: Aprendizagem prática. Educação. Extensão

\section{INTRODUÇÃO}

O Laboratório de Tecnologias Avançadas em Iluminação e Instalações Elétricas, integrante do Centro de Excelência em Eficiência Energética da Amazônia (CEAMAZON), viabiliza aos discentes de graduação da Universidade Federal do Pará projetos integradores que auxiliam na formação em Engenharia Elétrica, visando suprir as necessidades exigidas no mercado, que constantemente busca priorizar a inserção de novos profissionais minimamente ambientados às dinâmicas entre os conhecimentos teóricos e técnicos de uma situação cotidiana.

As diretrizes curriculares nacionais (DCNs) para os cursos de Engenharia dão mais liberdade para as instituições estabelecerem seus currículos e não se prenderem a conteúdos ou currículos mínimos, sendo assim valorizado o desenvolvimento de competências técnicas e socioemocionais importantes para o exercício da profissão de engenheiro, qualquer que seja sua modalidade. Ou seja, não é apenas saber, mas saber fazer (NITIZ, 2020). 


\section{JUSTIFICATIVA}

A vivência de experiências em ambientes fora da universidade possibilita ao discente um contato com as atividades desempenhadas por um profissional de engenharia elétrica, mostrando que a prática é tão importante quanto os conhecimentos teóricos adquiridos em sala de aula, tornando mais eficiente a preparação do discente para o mercado de trabalho. Essa condição pode ser notada, por exemplo, nas etapas que constituem a realização de um projeto elétrico, que vão desde o primeiro contato com o cliente até a revisão final e entrega da planta baixa para o mesmo, que se tornam muito importantes para o desenvolvimento de um senso crítico capaz de analisar e resolver determinados problemas que poderiam ser encontrados no âmbito profissional.

Visitas técnicas aos locais para levantamento da situação e realização de medições, análise da situação estrutural do edifício, verificação da infraestrutura elétrica já existente e criação da planta baixa da residência, que causam o desdobramento do projeto elétrico, proporcionam um primeiro contato com o cliente e possibilitam um relacionamento melhor entre as partes envolvidas, alcançando assim uma boa sintonia para evitar decepções que podem acarretar em uma impressão negativa dos serviços prestados pelos discentes. Além disso, as revisões feitas pela professora responsável, instigam questionamentos e discussões de novas ideias, sendo parte fundamental para agregar conhecimento e familiarização do aluno com rotinas de trabalho encontradas na profissão.

Os alunos passam a integrar a equipe do laboratório com o intuito de alavancar o seu conhecimento na área, criando assim uma expectativa com o nível de aprendizagem que será adquirido. Nesse sentido, alguns engenheiros que fizeram parte da equipe como alunos e hoje estão no mercado de trabalho, relatam o seu nível de experiência alcançado com a ajuda das atividades desenvolvidas durante a sua passagem pelo laboratório. Desse modo, o artigo tem o intuito de levantar e apresentar dados que comprovam a importância de conhecimentos práticos no ambiente da faculdade para o amadurecimento na formação do engenheiro eletricista.

\section{METODOLOGIA}

\subsection{Aplicação de normas técnicas}

Estar em conformidade com normas pode poupar tempo, esforço e despesas, garantindo a tranquilidade de estar de acordo com as responsabilidades legais, por isso, os projetos elétricos residenciais são desenvolvidos de acordo com as normas técnicas e regulamentadoras, ganhando credibilidade nos padrões de segurança, qualidade e menores chances de erros. Todos os discentes são incentivados a estudar as normas nacionais e as normas da concessionária de energia local, desenvolvendo assim uma maior confiabilidade nos serviços prestados (LEAL e OGASSAWARA, s.d.).

O dimensionamento dos condutores, eletrodutos e dispositivos de proteção; a divisão de cargas por circuitos; a distribuição de pontos de iluminação e tomadas, bem como o sistema de aterramento, devem ser feitos obedecendo os critérios técnicos das normas nacionais voltadas para instalações elétricas e as normas da concessionária de energia local. Deste modo, um projeto bem dimensionado e seguindo as orientações técnicas evita incêndios, curtos-circuitos, sobrecargas e outros problemas.

Já as normas regulamentadoras são importantes para segurança em trabalhos que envolvem, direta ou indiretamente, serviços que interajam com eletricidade, desde a etapa de projeto até a etapa de construção e manutenção das instalações elétricas. Esta norma também é 
crucial para as atividades desempenhadas nas bancadas didáticas, que necessitam de uma atenção especial devido aos riscos presentes.

\subsection{Práticas com softwares}

O laboratório de instalação elétricas disponibiliza aos discentes participantes ferramentas que visam otimizar as etapas de elaboração dos projetos elétricos. O conhecimento e a experiência na utilização de ferramentas que tem ampla utilização no mercado de trabalho agregam conhecimento ao complementarem a formação acadêmica, uma vez que é comum a falta de familiarização com esses softwares.

Para a elaboração do desenho da planta baixa é utilizado um software CAD, tecnologia de desenho assistido por computador, que auxilia na documentação técnica que substitui os desenhos no papel por um processo computadorizado, permitindo a representação de entidades geométricas planas em 2D ou mesmo objetos em 3D com maior precisão. É amplamente utilizado por engenheiros, arquitetos e profissionais da construção (AUTODESK, s.d.).

Visando automatizar etapas de projetos de instalações elétricas, proporcionando maior produtividade, qualidade e detalhamento do projeto, são utilizados programas para elaboração de projetos elétricos residenciais e prediais, que aproveitam os desenhos arquitetônicos feitos para a elaboração dos mesmos e garantem maior confiabilidade, uma vez que seguem os parâmetros das normas da Associação Brasileira de Normas Técnicas (ABNT), (MULTIPLUS, s.d.).

Além disso, o planejamento do sistema de iluminação que calcula e visualiza a intensidade luminosa para áreas internas e externas, desde prédios inteiros e salas individuais até vagas de estacionamento ou iluminação pública, também faz o uso de softwares próprios para o design de iluminação, possibilitando a simulação desses ambientes com as especificações de produtos reais encontrados no mercado (DIAL, s.d.).

\subsection{Práticas em bancadas didáticas}

Entende-se que parte dos profissionais recém-formados que ingressam no mercado de trabalho possuem, em grande parte, uma ampla formação teórica, porém apresentam inseguranças e limitações em execuções e montagens práticas. Sendo assim, o laboratório disponibiliza aos alunos experiências práticas através de bancadas equipadas com componentes e instrumentos que contribuem para a consolidação do conhecimento teórico em instalações elétricas prediais e industriais. De certa forma, este conhecimento oferece aos alunos não só um contato mais próximo com os dispositivos utilizados, mas também confiança na execução e capacitação para o mercado de trabalho. Além de que, uma das finalidades dos experimentos práticos é desenvolver a capacidade de resolver problemas e auxiliar na compreensão dos conceitos básicos devido ao contato direto com fenômenos que os capacitam à manipulação de materiais e equipamentos (GUIMARÃES, 2017).

São disponibilizados aos alunos diversos dispositivos como interruptores, relé foto elétrico, dimmer e RGB (Red Green Blue), mostrando as opções de acionamentos e como cada um deles pode se encaixar no seu dia a dia. A execução dessas experiências acaba por ampliar/fortalecer o conhecimento teórico e fomenta o desenvolvimento prático. Além disso, as bancadas também recebem equipamentos para realizar experimentos de instalações elétricas industriais, como os simuladores de defeitos de partidas de motores, que possibilitam aos discentes o aprendizado de princípios básicos correlatos aos campos de controle e comando, que são de suma 
importância para a formação dos estudantes. Com isso, pratica-se a montagem dos circuitos com componentes variados e potencializa-se a interpretação dos diagramas unifilares.

Com essas práticas, os alunos enfrentam os resultados não previstos desafiando o seu raciocínio, levantando questões para a investigação, elaboração de hipóteses, organização e interpretação de dados (GUIMARÃES, 2017).

\subsection{Visitas técnicas}

Além do conhecimento teórico desenvolvido na graduação, a visualização de situações cotidianas contribui para impulsionar futuras tomadas de decisão no campo de atuação do engenheiro. As visitas técnicas realizadas ainda na universidade cumprem a finalidade de desenvolver o projeto elétrico do local solicitado dentro das perspectivas sugeridas nas Normas Técnicas, além de verificar as possíveis divergências entre o consumo esperado pelo cliente e os valores cobrados nas contas de energia pela concessionária. Os discentes seguem o algoritmo de análise do ambiente, que considera: a localização do ramal de entrada, lay out, pontos de luz e tomadas existentes, tomadas de uso específico e arranjo do aterramento. Também são observadas as características do imóvel e as necessidades de consumo energético do cliente para as prováveis intervenções no projeto.

A experiência adquirida por meio dessa metodologia pode proporcionar ao recém-formado o conhecimento base necessário para o desenvolvimento de atividades envolvendo projetos elétricos prediais ou industriais que visam a implantação ou a manutenção dos elementos pertencentes ao escopo de trabalho do então engenheiro.

\subsection{Abrangência das atividades do laboratório}

O projeto de extensão ofertado pelo laboratório engloba o atendimento às famílias de baixa renda para a elaboração do projeto elétrico e abrange diversos bairros da Região Metropolitana de Belém, como mostra a Figura 1. Além disso, oferece minicursos de instalações elétricas residenciais e comandos elétricos industriais para os alunos de nível técnico das instituições federais da região, palestras aos alunos do terceiro ano do ensino médio de escolas públicas abordando conceitos básicos de eletricidade para complementar nos estudos para o ENEM e também, palestras associadas ao uso correto da energia elétrica e eficiência energética, objetivando estimular a economia de energia e o seu uso racional. Portanto, essas atividades estimulam não somente as qualidades e conhecimentos técnicos referentes ao curso de graduação, também são responsáveis por proporcionar o contato entre aluno e comunidade, estimulando uma formação mais humanística, critica e reflexiva pertinente aos aspectos sociais e econômicos da sociedade. 
Figura 1 - Abrangência dos projetos de instalações elétricas.

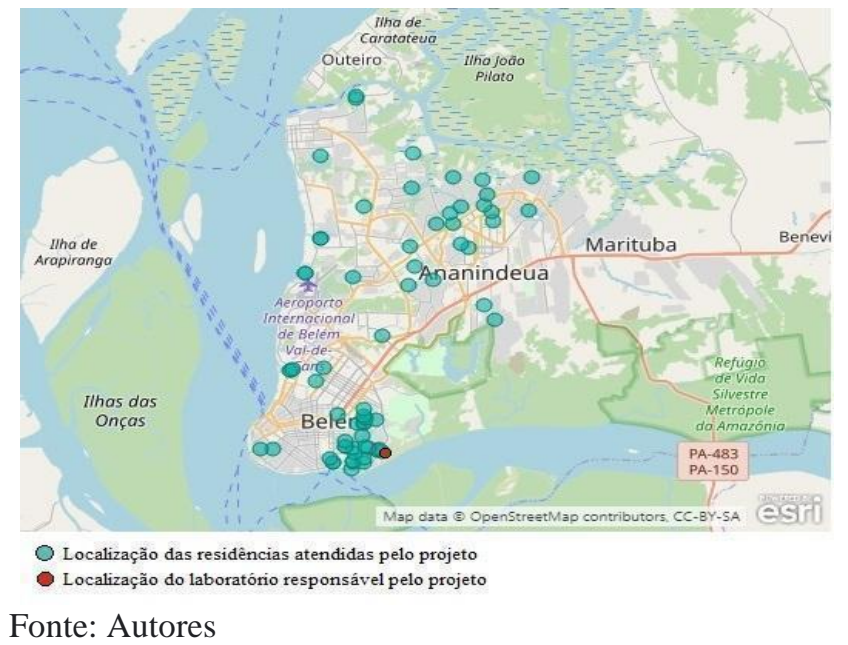

O laboratório também participa do Programa Institucional de Bolsas de Iniciação Científica (PIBIC), que auxilia nas produções de pesquisa dos alunos, do Programa LABINFRA, que contribui na ampliação das ações de qualificação da infraestrutura do laboratório, de projetos de pesquisa como o Sistema de Gestão de Energia Elétrica (SISGEE), que realiza estudos sobre a qualidade de energia e promove a eficiência energética em edificações da universidade através do Programa Brasileiro de Etiquetagem (PBE Edifica), e também recebe demandas de projetos elétricos e luminotécnicos para edifícios que serão construídos dentro da universidade, como o Clube de Ciências e o Complexo Cultural Cinema, Livraria e Editora (PROEG, 2018).

A participação nesses programas e projetos possibilita uma visão acadêmica e profissional mais abrangente da engenharia e áreas afins, oferecendo aos alunos vivência com uma equipe multidisciplinar e a oportunidade de expor suas opiniões, ser analítico, crítico e reflexivo, contribuindo para o desenvolvimento de habilidades, experiência com trabalho em equipe e formação do futuro profissional de engenharia.

\subsection{Levantamento avaliativo}

Com o intuito de avaliar a perspectivas do estudante de engenharia elétrica e do engenheiro atuante na profissão sobre a relevância das atividades realizadas no Laboratório de Instalações Elétricas como contribuição para o mercado de trabalho, foi feito o levantamento da opinião dos participantes utilizando a plataforma de pesquisas Google Forms. Foram elaborados formulários direcionados aos atuais integrantes (discentes da graduação) e aos já formados há pelo menos 2 anos, com respostas compreendidas entre 1 (indicando menor relevância) e 5 (indicando maior relevância). Foram entrevistadas 26 pessoas, sendo 16 estudantes e 10 graduados.

As perguntas dispostas no formulário levantam a opinião das duas perspectivas apresentadas, do ponto de vista do discente, as expectativas, e do ponto de vista dos já formados, a contribuição para a formação, relacionadas a sete tópicos: conhecimento acerca da elaboração de projetos elétricos, conhecimento dos softwares utilizados, realização de visitas técnicas, contato com a comunidade, revisões e discussões envolvendo os projetos de instalações elétricas, experiências prediais e industriais realizadas no laboratório e por fim, como o projeto de extensão é avaliado de maneira geral. 


\section{RESULTADOS}

Os gráficos da Figura 2 comparam as opiniões sobre o quão relevante foram as práticas de elaboração de projetos elétricos, sendo bem pertinentes, visto que esse exercício possibilita o melhor entendimento de métodos já mencionados, como a aplicação de normas técnicas ou o contato com projetos reais, que poderão receber uma futura implementação. E a Figura 3 relata como o auxílio de softwares complementares são bem vistos, em sua maioria, tanto para estudantes quanto para formados, uma vez que a habilidade com os mesmos é considerada um diferencial para candidaturas em empresas que fazem o uso de tais recursos em suas atividades profissionais.

Figura 2 - Em relação aos projetos de instalações elétricas.

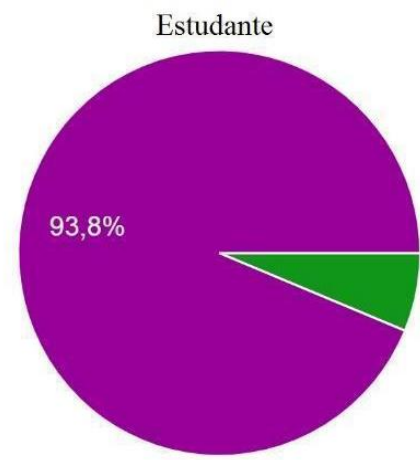

Fonte: Autores

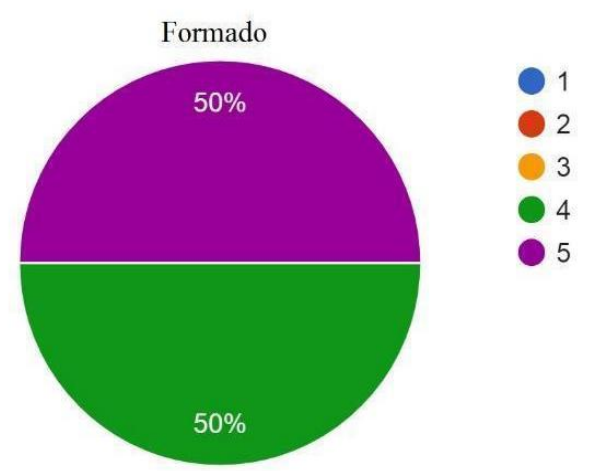

Figura 3 - Considerando os softwares utilizados no laboratório.
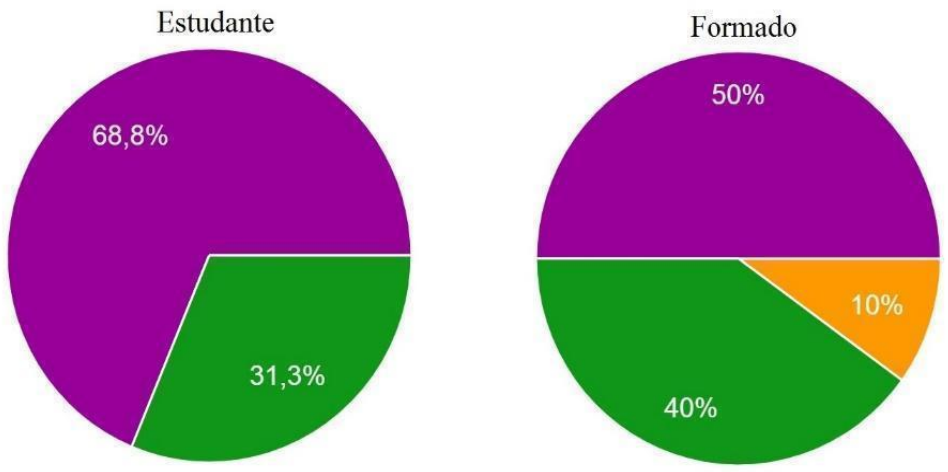

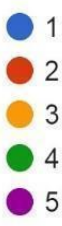

Fonte: Autores

Ademais, em relação às visitas técnicas, como demonstra a Figura 4, houve uma aceitação mediana entre a comunidade estudante, porém, ocorreu uma maior valorização dos já formados. Isso implica a necessidade de aquisição de métodos, pela coordenação do laboratório, que confirmem para os discentes a importância do melhor aproveitamento dessas técnicas, que possuem papel básico na formação do engenheiro, o qual irá participar ativamente da proposta à consolidação de uma planta. A Figura 5 também é um demonstrativo de uma das consequências que originam de uma visita técnica ou palestra, que é o valor do contato com a comunidade. A maior aceitação do público egresso ratifica a necessidade de compreensão da visão do indivíduo que será beneficiado com o serviço prestado, possibilitando a satisfação do trabalho final tanto para o cliente, quanto para o engenheiro. 
Figura 4 - Em relação as visitas técnicas.
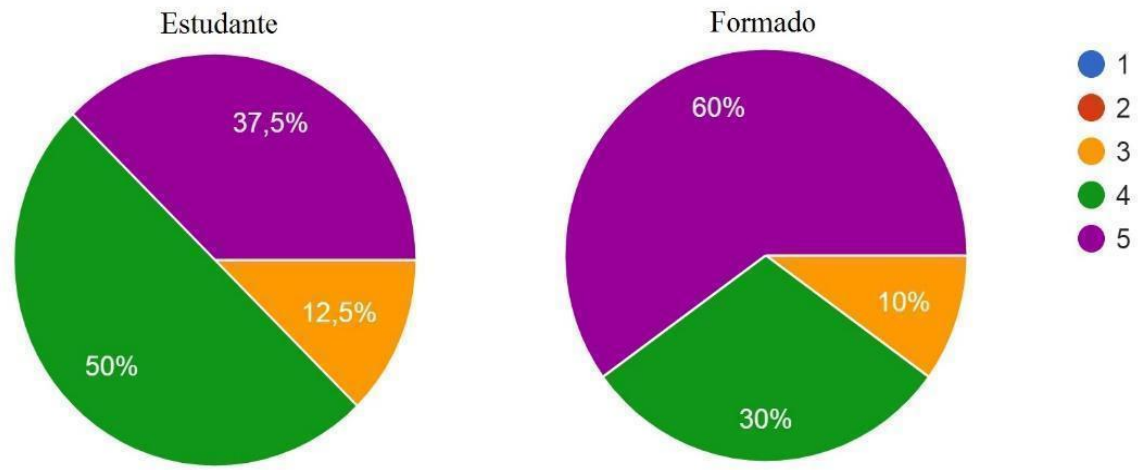

Fonte: Autores

Figura 5 - Contato com a comunidade.
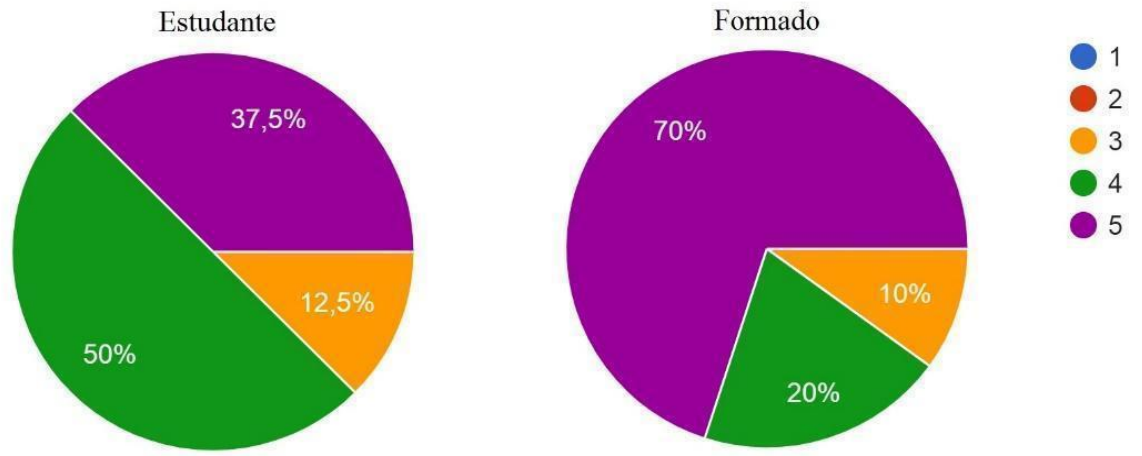

Fonte: Autores

As revisões e discussões dos projetos elétricos em desenvolvimento visam propor soluções considerando não apenas técnicas corretas, mas abordando os problemas em sua totalidade, e apresentaram bastante aceitação como forma de aprendizagem pelos alunos e formados, sendo indicado na Figura 6. As experiências didáticas realizadas pelos participantes também foram aceitas em sua grande maioria, como visto na Figura 7, reforçando os benefícios que a vivência prática, mesmo que de modo simplificado, pode promover ao consolidar a base teórica e colaborar para a solução de problemas em situações reais, presenciadas no cotidiano predial ou industrial.

Figura 6 - Revisões e discussões acerca dos projetos de instalações elétricas.
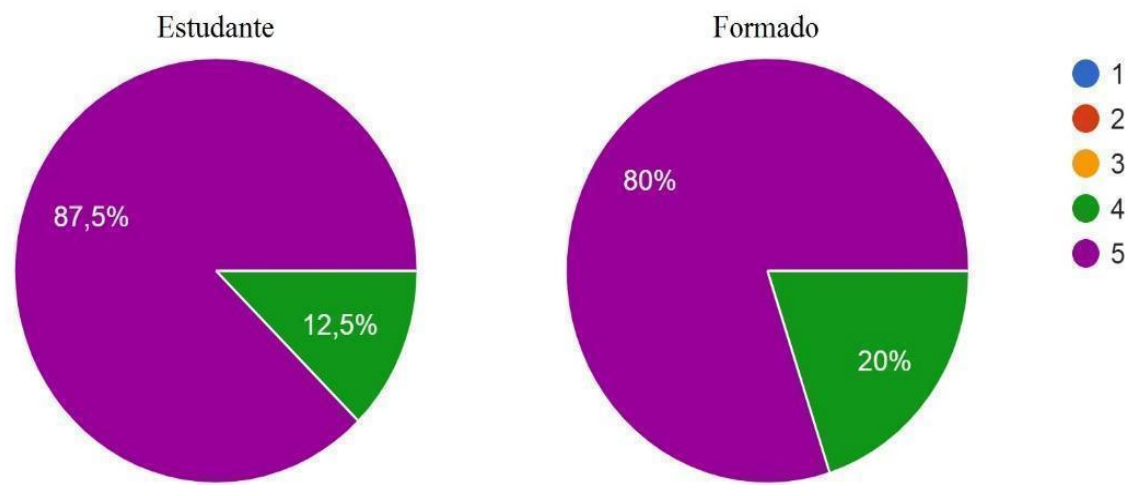

Fonte: Autores 
Figura 7 - Experiências prediais e industriais realizadas no laboratório.
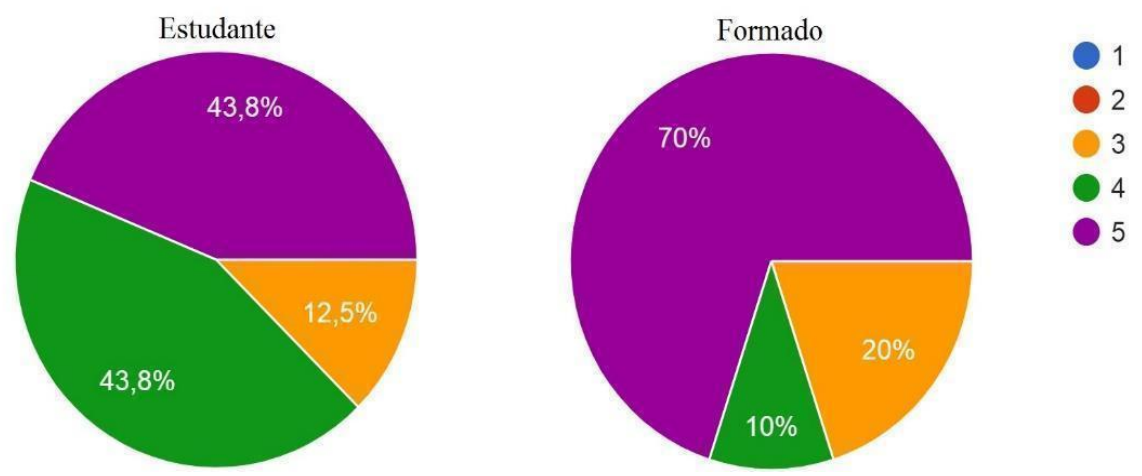

Fonte: Autores

Finalmente, a Figura 8 ilustra que as expectativas sobre o projeto de extensão mostram-se bem promissoras aos que ainda estão atuando na graduação, e, aos graduados, os ganhos provenientes dessas ações são confirmados.

Figura 8 - Expectativa com o projeto de extensão.
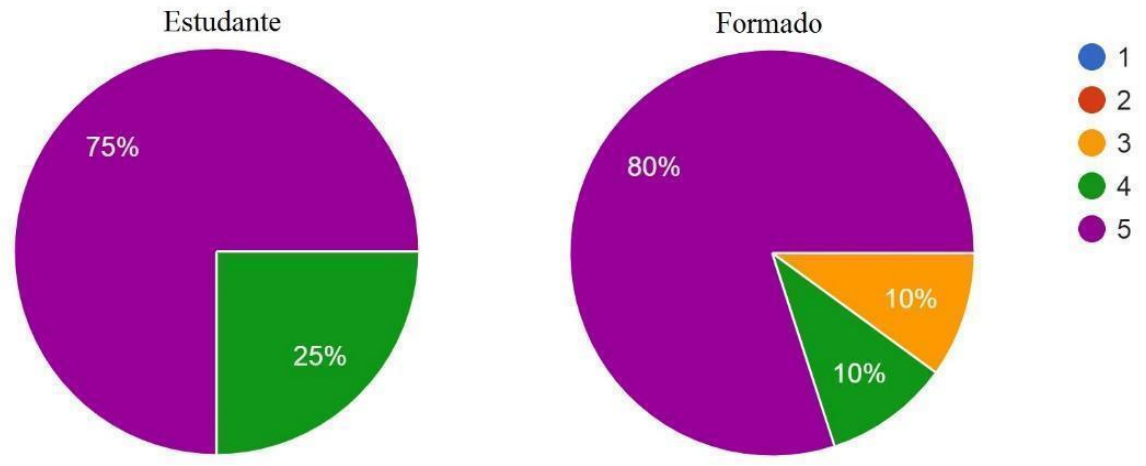

Fonte: Autores

\section{CONSIDERAÇÕES FINAIS}

O Laboratório de Instalações Elétricas cumpre um papel importante no âmbito acadêmico, pois além de complementar a formação de futuros engenheiros, estende as ações da universidade com o intuito de atender as necessidades da comunidade em geral. Desse modo, além de inserir o aluno em atividades práticas semelhantes às do mercado de trabalho, a participação nas atividades do laboratório permite ao discente enxergar o seu papel de agente transformador da realidade social.

Mapear as expectativas dos alunos ajuda a entender as necessidades na formação dos voluntários, permitindo que as metodologias aplicadas sejam direcionadas para obter maior aproveitamento. Por outro lado, o levantamento realizado junto aos membros já graduados é de grande ajuda para entender de que modo o projeto impactou na sua formação.

Segundo os dados levantados, é perceptível que para os alunos há uma expectativa positiva acerca da relevância das atividades desenvolvidas para a complementação da sua formação. Além do mais, os dados mostram também que para os engenheiros formados, as atividades desenvolvidas de fato tiveram um papel relevante na sua preparação para o mercado de trabalho. 


\section{REFERÊNCIAS}

AUTODESK. Software Cad. Disponível em: https://www.autodesk.com.br/solutions/cadsoftware. Acesso em: 14 jul. 2020.

DIAL. DIALux is the software for professional lighting desingn. Disponível em: https://www.dial.de/en/dialux/. Acesso em: 14 jul. 2020.

MULTIPLUS. Softwares técnicos: Projetos elétricos PRO-Elétrica. Disponível em: https://multiplus.com/software/pro-eletrica/. Acesso em: 14 jul. 2020.

NITZ, M. O que o mundo espera da educação em engenharia. Ensino superior, [S.I] 2020. Disponível em: https://revistaensinosuperior.com.br/educacao-engenharia-diretrizes/. Acesso em: 14 jul. 2020.

PRÓ-REITORIA DE ENSINO DE GRADUAÇÃO - PROEG. Programa LABINFRA 2019Edital $\mathbf{n}^{\mathbf{0}}$ 08/2018. Disponível em: http://www.proeg.ufpa.br/index.php/noticias/258programa-labinfra-2019-edital-n-08-2018. Acesso em: 15 jul. 2020.

OGASSAWARA, N. J.; LEAL, L. A. B. Normas técnicas - Aplicação opcional ou compulsória, PDCA Engenharia. Disponível em: http://www.pdcaengenharia.com/normastecnicas-aplicacao-opcional-ou-compulsoria/. Acesso em: 22 set. 2020.

GUIMARÃES, Evandro V. Produto educacional - Sequência didática: Práticas experimentais reais e virtuais. Guarapuava, 2017. Disponível em: https://www3.unicentro.br/wp-content/uploads/sites/28/2017/12/Produto-Educacionalaplicado.pdf. Acesso em: 23 set. 2020. 


\title{
THE IMPORTANCE OF PRACTICAL ACTIVITIES FOR THE ENGINEER'S PROFESSIONAL DEVELOPMENT
}

\begin{abstract}
The application of the knowledge acquired in the academic environment provides an approximation between theory and practice. Thus, this article was elaborated based on a research on the importance of practical learning for students of Electrical Engineering at the Federal University of Pará who participate in the extension activities promoted by the Laboratory of Advanced Technologies in Lighting and Electrical Installations of Ceamazon (Center of Excellence in Energy Efficiency in the Amazon) and those already trained who passed through the mentioned laboratory. The performance in the elaboration of electrical projects, in experiments of electrical installations and in monitoring mini courses allows a higher domain of the knowledge absorbed in the theoretical disciplines and technical standards. The circumstances and difficulties faced during the implementation of those activities, encourage the development of a professional character within the students, thus, consequently, providing a better qualification for the activities found in the labor market.
\end{abstract}

Keywords: Practical learning. Education. Extension 